\title{
EL LECTOR COLECTIVO EN LA OBRA LITERARIA DE ENRIQUE VILA-MATAS
}

\author{
Julia GONZÁLEZ DE CANALES
}

Université de Neuchâtel

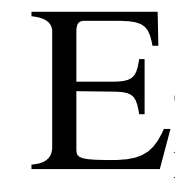
ste artículo pretende estudiar la relación que la obra de Enrique Vila-Matas mantiene tanto con la industria editorial como con el conjunto de lectores que conforman la esfera de lo público. El lector es aquí considerado más allá de su singularidad individual, en su carácter de lector colectivo.

En 1973 Jürgen Habermas definió la esfera de lo público como «un campo de nuestra vida social en el que se puede formar algo así como opinión pública. Todos los ciudadanos tienen -en lo fundamental- libre acceso a él» (Habermas, 1973: 61). Dicha opinión pública se forja en torno a aquellos aspectos de interés general para una determinada sociedad y es inseparable de los intereses de instituciones externas al autor y su obra: casas editoriales y jurados de diversa índole que se presentan como marcadores de las preferencias y tendencias literarias del momento, influenciando en la opinión de los miembros de la sociedad civil.

Todos formamos parte de ella, incluido Vila-Matas. El catálogo de publicaciones que conforman su obra es extenso: treinta y cinco libros que han sido traducidos a más de veinticinco idiomas, así como numerosos artículos periodísticos y prólogos a múltiples ediciones. Su primer libro lo publicó en 1973 pero no fue hasta 2001 que empezó a recibir premios por su obra. Desde entonces ha conseguido algunos de los más importantes en el mundo literario: el XII Premio Internacional de Novela Rómulo Gallegos por El viaje vertical, el Prix du Meilleur Livre Étranger por Bartleby y compañía, el XX Premio Herralde de Novela y el Prix Médicis de novela extranjera por El mal de Montano, los premios de la Real Academia Española y el Letterario Internazionale Mondello por Doctor Pasavento, así como el reciente Cuhnambebe Award por Dublinesca.

Dichos galardones han incrementado el reconocimiento de su obra y han colaborado a la construcción de un imaginario común que concibe los libros del autor como un producto de asegurado éxito comercial. Mucho parece pues haber cambiado entre la época en la que Vila-Matas era un escritor completamente desconocido para una gran parte del público receptor y el momento actual, en el que sus obras permanecen durante semanas en la lista de los libros más vendidos. 
Para entender mejor esta primera etapa cabe señalar que Vila-Matas empezó a escribir a temprana edad y sus primeras publicaciones eran seguidas y apreciadas en España por una pequeña minoría de lectores que valoraba la voluntad del autor por distanciarse de la estética realista que predominaba en las producciones artísticas del país. Su situación se correspondía con la de muchos otros escritores que si bien obtuvieron el reconocimiento entre algunos sectores de la crítica, no consiguieron que ese entusiasmo se trasladara a un público lector más amplio, es decir, no conseguían vender. De acuerdo con el pensamiento de Pierre Bourdieu, su estado era limítrofe con el del fracaso: se encontraba en el indeterminado punto que separa la frustración personal y provisional del artista maldito, del fracaso a secas del fracasado.

Salvando las distancias, el caso de Vila-Matas era parecido al de James Joyce, quien, como cuenta el autor barcelonés, a pesar de su innegable talento, tuvo que soportar hasta veintidós veces el rechazo de su manuscrito Dublineses antes de verlo publicado. Aunque, añade, si sirve de algún modo de consolación, «no hay un solo escritor de éxito que escape del rechazo, porque éste llega por todas partes: en forma de una mala crítica, un premio que no le dan, ventas decepcionantes, un amigo que se ríe de él y de sus pretensiones, etcétera» (Vila-Matas, 2003: 107-108).

De manera pareja, Vila-Matas tuvo que esperar diez años hasta conseguir que Historia abreviada de la literatura portátil alcanzara una amplia, si bien no masiva, aceptación. Parece, pues, que por aquellos tiempos su suerte no corría por España sino más bien por México o Francia, países que rápidamente otorgaron prestigio a su obra. Sólo al cabo de los años, cuando Vila-Matas ya vendía libros de forma regular, las instituciones españolas se decidieron a otorgarle el Premio Ciutat de Barcelona y, posteriormente, el Nacional de la Crítica, un reconocimiento que, aunque bienvenido, llegaba algo tarde y a remolque.

Es difícil saber cuál fue el momento o punto de viraje que produjo la transformación del reducido público receptor de su obra a fenómeno de masas. Aunque quizás Bourdieu tenga razón y, como argumenta acerca de la oferta y la demanda, no haya que buscar mayores explicaciones ya que «cuando una obra encuentra a su público, que la comprende y la aprecia, casi siempre se debe al efecto de una coincidencia, de un encuentro entre series causales parcialmente independientes, y no al producto de una búsqueda consciente del ajuste a las expectativas de la clientela» (Bourdieu, 1999: 396). Dicha afirmación, si bien aligera la pregunta por la metamorfosis de la recepción colectiva de su obra, no elimina el núcleo de la duda, la abre a nuevas cuestiones, como por ejemplo, la adecuación, o no, de la denominación best-seller para la clasificación de los libros del autor. De acuerdo con el estudio que David Viñas realizó al respecto, el concepto best-seller proviene de América, refiere al libro que mejor vende y acostumbra a ir asociado con una posición en la lista de los libros más vendidos. Su mala prensa se justifica por la creencia popular de que los best-sellers son libros comerciales, publicados en vista a un rápido beneficio económico y no, necesariamente, por su calidad literaria. Dicho en palabras de Viñas, «son obras pensadas para el puro entretenimiento y, por tanto, para ser rápidamente consumidas y olvidadas. Están llenas de trampas para cazar lectores. Su calidad literaria es más que dudosa. En rigor, no son literatura, sino otra cosa» (Viñas, 2009: 9). 
Vila-Matas parece compartir esta opinión, pues se refiere a ellos, y al engranaje publicitario que los rodea y apoya, de forma un tanto despectiva cuando afirma: «muchos escritores confunden su actividad con la resonancia social que ésta tiene y con el dinero. Son una plaga. Cada año uno de ellos gana el Premio Planeta. Los medios de comunicación, sólo por el dinero del premio, le dan una importancia impresionante y generalmente silencian la literatura de verdad» (Vila-Matas, 2003: 60). Los pocos casos que rehúyen ser clasificados bajo la característica exclusiva del estrellato comercial son denominados best-sellers de calidad: obras que, pese haber alcanzado el éxito de ventas, fueron escritas siguiendo criterios puramente estéticos propios de las obras maestras.

Frente al concepto de best-seller está el de steady-seller: libros que «han dejado ya de estar entre los más vendidos pero siguen vendiéndose regularmente y llegan a adquirir una cierta estabilidad en el éxito de ventas. Si esta estabilidad se mantiene durante mucho tiempo, durante siglos incluso, nos encontramos frente a long-sellers» (Viñas, 2009: 10) o best-sellers de larga duración, lo que les otorga cierto estatus.

De acuerdo con esta clasificación, cabe plantearse qué categoría representa mejor la obra de VilaMatas. Como ya se ha indicado, las ventas de los libros del autor han crecido de forma exponencial a lo largo de los años. En sus inicios como escritor, tuvo que definirse dentro del campo literario, demostrar su calidad y marcar la diferencia con otros escritores nacionales. Sin embargo, a partir de la publicación de Historia abreviada de la literatura portátil el éxito pareció empezar a acompañar al autor sin que ello disminuyera la calidad de sus publicaciones.

La preocupación por conservar y ejercer una literatura de calidad ha inquietado al autor desde sus inicios. Aunque no entendamos nada, Y Pasavento ya no estaba o Dublinesca son algunos de los títulos que lo reflejan. En el primero, Vila-Matas trae a colación una supuesta cita de Arthur Schopenhauer ${ }^{1}$ para abogar a favor de la buena literatura y poner en evidencia la falsa relación lógicacausal entre ésta y la otorgación de premios por parte de la industria editorial. Así, según el autor, «éstos no tienen importancia, y a todos nos deberían traer sin cuidado, y sin embargo se habla mucho de los premios, que se confunden con los textos, se difuminan bajo el color del oro» (Vila-Matas, 2003: 60). De la misma manera, el ensayo «Una narrativa invisible» supone una mirada crítica hacia el poder del mercado. En él, el autor denuncia la llamada «nueva narrativa española», que tuvo lugar en los años ochenta:

[...] eran entonces la gran mayoría de escritores españoles muy jóvenes y activos y nadie intuía que tardarían muy poco a apoltronarse y ser seducidos por el mercado; fueron engullidos por la repentina necesidad de comprarse chalets con piscina o bien por llevar una vida de correctos académicos (imaginarios o no). Hoy en día no queda casi nada de aquella narrativa que pudo impactar Europa (Vila-Matas, 2008: 136).

\footnotetext{
${ }^{1}$ «Nunca se leerá demasiado poco lo malo, ni con exceso lo bueno. Los libros malos son un veneno intelectual que destruye el espíritu. Y porque la mayoría de las personas, en lugar de leer lo que se ha producido de mejor en las diferente épocas, se reduce al círculo estrecho de las ideas en circulación, y el público se hunde cada vez más profundamente en su propio fango» (Vila-Matas, 2003: 59).
} 
Esta preocupación por la salud de la literatura española, la traslada Vila-Matas años más tarde también a Dublinesca, personificada en Riba: un apasionado lector que no puede entender «el becerro de oro de la novela gótica, que forjó la estúpida leyenda del lector pasivo» (Vila-Matas, 2010: 71) y que en los últimos años se ha puesto tan de moda. La lectura de estas novelas no tiene, para el personaje, ningún valor, ya que él está acostumbrado a publicar sólo long-sellers o jóvenes promesas, aunque ello suponga un gran riesgo para su empresa.

De acuerdo con los postulados de Bourdieu, cabe interpretar que la editorial de Riba no se encuentra en el polo heterónomo del campo literario, «favorable a los que dominan el campo económica y políticamente (p. ej., el arte burgués)» (Bourdieu, 1989-1990: 22), sino en el autónomo, al resultar «poseedor de un gran capital específico, pero de escaso éxito en el público» (Bourdieu, 1989-1990: 25). Esto es, cada vez que Riba decide publicar un libro de un autor novel la empresa pasa por un período de gran incertidumbre. A pesar de ello, el personaje no está dispuesto a abandonar la búsqueda del autor genial ya que, en caso de que algún día llegara a encontrarlo, su propio valor generaría grandes beneficios para la editorial, empresa que se ha visto obligado a cerrar por pérdidas económicas persistentes.

En lo referente al propio Vila-Matas, el autor se ha ido aproximando desde el extremo del polo autónomo, que marcó sus inicios experimentales como escritor, a las orillas del polo heterónomo en el que se encuentra actualmente. Dicha traslación está marcada por dos momentos claves: su fichaje por Anagrama y la posterior unión a Seix Barral. Con la primera casa editorial, el autor publicó la mayor parte de sus libros, hecho que supuso un gran salto cualitativo en su carrera, ya que Anagrama posee un sello de calidad reconocido dentro del mundo editorial internacional. Con la segunda, Vila-Matas dio el paso definitivo para llegar a ser conocido por el gran público. Su contrato con Seix Barral le asegura una gran difusión de su obra: de la futura, pero también de la pasada, gracias a la reimpresión de sus obras reunidas en las colecciones De Bolsillo, sello perteneciente a la multinacional Planeta. Gracias a ello, los libros del autor se encuentran ya disponibles, no sólo en librerías especializadas en humanidades, sino también en grandes almacenes y quioscos de los aeropuertos.

La popularización de su obra, sin embargo, no ha conllevado una disminución de la calidad de su escritura, al contrario. Desde que comenzara a escribir, Vila-Matas no ha dejado nunca de plantearse retos formales y estilísticos para cada nueva publicación. Por ello, se puede afirmar que, si bien el número de ventas de los libros del autor ha aumentado de forma considerable en los últimos años, el papel de revolucionario de la literatura española, adoptado en los años ochenta ${ }^{2}$, sigue vigente. Este hecho, junto a su incombustible espíritu de superación, lo convierte en un escritor con un bagaje literario lo suficientemente arriesgado y una valía artística ampliamente demostrada como para poder ser catalogado bajo el desprestigiado rubro de autor best-seller. En todo caso se acercaría al de steadyseller: una categoría mucho más agradable al asegurar la supervivencia económica y rebajar el grado

\footnotetext{
${ }^{2}$ «Yo creo que ese problema lo he roto de fuera hacia dentro, trabajando contra el superficial canon nacional que algunos críticos nefastos crearon en los años ochenta. En vista que no encajaba en esa narrativa nueva española (donde se jaleaba la mera copia de los mejores estilistas del famoso boom latinoamericano), opté por escribir una literatura no nacional española» (Vila-Matas, 2008: 136).
} 
de dependencia con respecto a las demandas del mercado. Además, los autores de steady-sellers disponen de una legitimidad que les es ajena a los de best-sellers: son considerados autores de prestigio tanto por sus lectores como por el aparato crítico, hecho que, acorde con la perspectiva de Bourdieu, ratifica el carácter artístico de su obra.

Según el pensador francés, «la obra de arte es un objeto que sólo existe como tal por la creencia (colectiva) que lo conoce y lo reconoce como obra de arte» (Bourdieu, 1989-1990: 20), es decir, existe si la sociedad en su conjunto la acepta como tal. Los libros de Vila-Matas cumplen con este requisito. Su obra es tomada en consideración por el lector colectivo: el gran público, los críticos literarios, los editores y los académicos, esto es, los organismos que, según Jan Mukařovský, «influyen sobre el valor estético, regulando la valoración de las obras de arte» (Mukařovský, 1977: 83). Todos ellos consideran que, a pesar del éxito, sus libros no han perdido el vínculo con el campo artístico autónomo y, por ello, le otorgan a Vila-Matas la legitimidad de llamarse autor. En otras palabras, el valor de una determinada obra no depende del artista, sino del campo en la que ésta se enmarca, así como de la confianza en el poder creador del escritor que los agentes de dicho campo le atribuyen. Éstos conforman un determinado conjunto que puede ser entendido como colectividad. En ella las tensiones, fruto de la lucha por la imposición de un determinado canon estético por encima de los demás, son comunes y se ven afectadas por la jerarquía social establecida.

De acuerdo con Mukařovský, «cada clase social e incluso cada medio (por ejemplo, el campo o la ciudad) tienen su propio canon estético que pasa a ser uno de sus rasgos más característicos» (Mukařovský, 1977: 73). A su vez, cada individuo determina una selección de libros o autores relevantes para él. La elaboración de tal canon particular no busca resaltar la permanencia categórica de dicha lista, sino más bien la fugacidad de un sujeto que se aferra a su gusto personal para soslayar la contingencia de una vida. El cúmulo de factores que influyen en la articulación de su decisión tiene que ver con la función estética del arte y con su forma de entenderla. La selección de los criterios que la definen viene influenciada por el aparato crítico y publicitario de la industria editorial, por las instituciones del poder político y por las opiniones de otros lectores. Es por ello que Mukařovský afirma que «el carácter colectivo o incondicional de la valoración estética se refleja en los juicios estéticos individuales» (Mukařovský, 1977: 84) que, en última instancia, deciden qué libros comprar y qué autores considerar como los más destacados. En este sentido, si una gran mayoría de lectores se decide por la adquisición de los libros de Vila-Matas es porque éste ha conseguido lo que otros muchos escritores desean: obtener no sólo el capital económico, sino también el simbólico, esto es, el reconocimiento del público lector. Para alcanzar el primero es necesario contar con una posición pionera en las lista de ventas, así como con el apoyo los premios, mientras que para obtener el segundo hay que conseguir la autoridad y la admiración de los compañeros de profesión, de los colegas del gremio y del público lector. Todos ellos conforman la esfera pública y manifiestan su opinión a través de artículos periodísticos, encuentros literarios y foros de internet.

Dichas populares plataformas de expresión son herederas de los burgueses círculos de discusión que se conformaron en los siglos XVIII y XIX, en los salones, especialmente en los franceses y alemanes. 
En ellos se originaron, de acuerdo con Habermas, los conceptos «esfera de lo público» y «opinión pública» para designar el parecer de la clase burguesa (Habermas, 1973: 62). Su actitud crítica en torno a las circunstancias políticas y culturales del momento ha llegado hasta nuestros días. Actualmente, blogs literarios como el de Fernando Valls, el de Ana Rodríguez Fischer, el de Isabel Verdú o el de Javier Avilés, entre muchos otros, permiten la difusión y el intercambio de opiniones entre los autores y sus lectores. Un ejemplo al respecto es la entrada, titulada «Razones para amar y odiar a Vila-Matas», que Isabel Verdú posteó en su blog el día 30 de abril de 2010. La discusión que ésta generó entre la comunidad de internautas puede considerarse como una contribución más al conjunto de reflexiones que confirman la opinión pública. El capital simbólico, asociada a ella, se contrapone al capital económico. El primero es efímero mientras el segundo es duradero, aunque no asegura la supervivencia financiera. Por eso, el objetivo de todo escritor es que sus ganancias económicas encuentren su equivalente en reconocimiento, que su legitimidad, su poder y su valor como autor le permitan hacerse un nombre dentro del campo literario y también conseguir cierta estabilidad en sus ingresos. En palabras de Umberto Eco, ello se corresponde con el deseo, «por un lado, de no caer en el materialismo determinista y, por otro lado, el de no ignorar totalmente (por una equívoca exigencia de pureza y fidelidad a la autonomía de la obra) las relaciones de los fenómenos artísticos con el mundo en el que surgieron» (Eco, 1970: 38).

Resulta relevante que, desde la publicación de Dublinesca, libro con el cual el autor inauguró su etapa en Seix Barral, el sector editorial ha entrado a formar parte explícita de la temática habitual en los libros del autor. Sus últimos relatos desarrollan escenas en las que personajes directa o indirectamente involucrados con el mundo editorial se muestran críticos e irritados con la propia industria y sus mecenas. De ello es ejemplo la misma Dublinesca, donde el personaje de Riba retrata a sus colegas editores españoles como «fatuos y menos conocedores de la literatura de lo que aparentan: más superstars y egocéntricos que aquellos de sus autores a los que les cargan el sambenito de ser ególatras hasta extremos delirantes» (Vila-Matas, 2010: 266).

Asimismo, en el relato «Editores y agentes (un vértigo)», Vila-Matas presenta una historia de ficción que presenta una imagen empobrecida y ruin del entramado editorial. En ella, Molly ha heredado los derechos de la prometedora opera prima de su difunto marido. Por ello, llaman a su puerta numerosos agentes literarios que pretenden sacar partido de lo que se prevé que será el éxito editorial del momento. Bajo este marco, Vila-Matas desarrolla un relato estremecedor en el que dicha industria parece tener más parentesco con el modus operandi mafioso que con el de un venerable negocio cultural:

[...] sabe ella poco de los negocios alrededor de los libros, pero ahora le parece que ha empezado a saber algo. A Molly, por encima de todo, le impresiona ver que con el nuevo agente no ha escapado del círculo que, ya con el anterior agente, la llevaba nuevamente hacia el editor de gran ego y soberbia infinita. Comprende horrorizada que ha ido a parar, casi sin darse cuenta, al núcleo duro de la mafia mundial de la industria del libro. Más allá de aquel despacho en la cima, aquel gabinete extranjero -aquella especie de despacho oval de la literatura mundial-, ya no es nada más. Es como si un círculo diabólico se cerrara allí. En el negocio mundial del libro todos se conocen y están conectados y son cómplices de una bien atada bolsa financiera de perversa solidaridad gremial. Si quiere apartar la metafórica pistola que le ha puesto en la 
cabeza el agente que iba a salvarla, ha de saber qué hará muy bien si no da demasiadas vueltas a su horrible situación y se limita a firmar el contrato que le empujan a firmar (Vila-Matas, 2013: 30).

Dichos relatos trasmiten al lector la animadversión hacia un mundo despiadado y obcecado por dominar el polo económico, pero también el simbólico, del sector del libro. El primero refiere a las ganancias monetarias provenientes de la venta de libros. El segundo, a la reputación de la empresa, adquirida a través del valor de los autores que conforman su catálogo. Ambos polos están, a su vez, relacionados con el polo político en la otorgación de premios institucionales, como lo es, por ejemplo, el Premio Nacional de Literatura.

La publicación de los escritores seleccionados o ganadores de dicho premio conlleva siempre controversias. Un caso claro de ello, lo tenemos en el revuelo que causó el reciente rechazo de Javier Marías al premio concedido por el Ministerio de Educación, Cultura y Deporte por su libro Los enamoramientos. De acuerdo con la nota de prensa publicada en el periódico El País,

[...] el escritor sostiene que la razón principal es su voluntad de no querer ser etiquetado como autor «favorecido por este o aquel Gobierno» ni ser involucrado en juegos políticos, por lo que defiende que se habría negado a aceptar el galardón, prescindiendo del partido que estuviera en el poder. También influyó en su decisión el hecho de que muchos autores, entre ellos su padre, Julián Marías, y Juan Benet, Juan García Hortelano y Eduardo Mendoza, jamás recibieron un premio Nacional: Estos fueron maestros míos y si ellos no lo recibieron, pensaba: ¿Por qué habría de merecerlo yo? (Manrique Sabogal, 2012).

El acto de Marías es significativo y evidencia el valor político y simbólico asociado a los premios institucionales. Su rechazo puede ser también interpretado como resultado de la irritación que el lector colectivo siente ante la imposición de un determinado canon contemporáneo nacional. Pero el posicionamiento de Marías no es un caso aislado, coincide con parte de la opinión pública que defiende una posición crítica de la sociedad con respecto al poder político. En este sentido, y de acuerdo con Habermas, cabe entender la opinión pública como mediadora entre la sociedad, que es quien la genera, y el Estado que, en su posición de «adversario de la esfera de lo público» (Habermas, 1973: 61), ejerce su influencia y regulación política.

En palabras del propio Marías, «nada irrita más a un escritor que aquellos críticos, profesores y comentaristas culturales que insisten en etiquetarlo» (Marías, 2011). De igual manera, resulta irritante para el lector colectivo saberse manipulado por los intereses de la industria editorial. Al respecto se ha manifestado José Ramón Giner quien, en su artículo periodístico, se pregunta acerca de la necesidad de mantener certámenes literarios que, lejos de ensalzar la memoria de un escritor, están subyugados a las necesidades de las casas editoriales:

[...] hace tiempo que estos concursos dejaron de tener importancia literaria, y se convirtieron en un negocio para la industria editorial, que obtiene un indudable provecho de ellos. Los premios literarios forman hoy parte destacada del marketing editorial. Se trata, casi siempre, de operaciones comerciales cuidadosamente elaboradas por los departamentos de las editoriales, con el objetivo de promocionar a sus escritores. No quiero decir que en esto, como en todo, no haya sus excepciones y no existan premios creados con la mejor voluntad y garantía. Sin duda alguna, los hay. Pero, en la mayoría de los casos, su esencia se reduce a lo que acabo de decir: una acción comercial (Giner, 2013). 
La misma opinión parece tener Fernando Valls, quien sólo salvaguarda el Premio Herralde y el Premio de la Crítica de entre todos los galardones nacionales ya que, según él, «premios que marcaron una tendencia narrativa, como el Nadal o el Biblioteca Breve, hoy no desempeñan, literalmente hablando, papel alguno» (Valls, 2009: 206). Ambos premios siguen haciendo prevalecer la calidad como criterio de exigencia requerido, distanciándose así de aquellas empresas que desean imponer unos «criterios de valoración, mediante los cuales los autores valen lo que sus libros venden» (Valls, 2009: 208). Valls afirma que este modo de proceder está basado en «la idea de cultura como espectáculo» (Valls, 2009: 198) por lo que «presenta la literatura, confundiendo valor y precio» (Valls, 2009: 199). Ante los peligros de una sociedad dominada por la mercancía y el mercantilismo desbordado, Mario Vargas Llosa apelaba al deber social de los órganos de prensa, cuya «función es, también, orientar, asesorar, educar y dilucidar lo que es cierto o falso, justo e injusto, bello y execrable en el vertiginoso vórtice de la actualidad» (Vargas Llosa, 2009: 14).

La cuestión reside en el grado de independencia factual que estos medios poseen: su capacidad para mantenerse alejados de los intereses políticos y económicos de los grandes lobbies, fieles a sus criterios de objetividad, de denuncia social y crítica cultural. Dicho de otra manera, los medios deberían de evitar situaciones como la que narra Vila-Matas en su ensayo «Pujol y Marsé»:

[...] el fin de semana pasado, el telediario catalán abría su información cultural con tres largos minutos dedicados al Premi Prudenci Bertrana, otorgado a media luz en la ciudad de Girona. A continuación, en segundo lugar y despachando en diez segundos la noticia, se informaba a regañadientes de que Juan Marsé había ganado el Premio Europa, un galardón que, aunque en TV-3 no lo sepan, es de una importancia que en nada desmerece al Cervantes (Vila-Matas, 1995: 130).

En este caso, la queja del autor se perfila hacia el interés partidista de una determinada cadena televisiva pero dicha crítica se puede extrapolar a otros medios, lacayos del yugo político-económico. Un ejemplo de ello sería la amplia cobertura que cada año recibe el Premio Planeta por parte de todos los medios de comunicación del Estado Español, si bien es ampliamente sabido que la elección del ganador resta lejos de la rigurosidad literaria. Una prueba fehaciente de ello la encontramos en las memorias de quien fue director editorial de Plantea, Rafael Borràs Betriu. En su libro La guerra de los planetas se pueden leer las siguientes afirmaciones que, por sinceras, resultan brutales:

[...] hoy en día el montaje de un premio -al margen de la cuantía con que esté dotado- mueve millones; pensar que una empresa medianamente seria se expondrá a la catástrofe que supone que ninguna de las obras presentadas tenga un alto valor literario y comercial a un tiempo, es no saber de qué va el negocio (Borràs Betriu, 2005: 296; cursiva en el texto).

[...] cuando un periodista, seguramente poco avezado en lo que son los premios literarios, preguntó con más candor que Caperucita Roja cómo era posible que Soledad Puértolas (que había concursado al Planeta ocultando su nombre y el título de la obra con un doble pseudónimo) hubiera sido invitada al acto antes de ser conocido el fallo y, por ende, el nombre del ganador, una sonrisa cómplice recorrió la sala donde se celebraba la rueda de prensa (Borràs Betriu, 2005: 297).

En este contexto, las palabras de Sergio Pitol resultan tranquilizadoras: 
El lector colectivo en la obra literaria de Enrique Vila-Matas

[...] se ha sabido de premios literarios que desprenden un aroma a corrupción, a escándalo, cinismo y turbiedad, que se le quedan a uno en la memoria por décadas. Todo lo contrario a lo que suscita Vila-Matas. En parte, imagino, porque a este dandy, con gestos de Buster Keaton, le es imposible posar ante sus lectores o sus amigos como un intelectual pomposo, engreído, imperial, sino como un mero hombre de letras que jamás emite una respuesta absoluta, contundente ni totalitaria. Su elegancia, su cortesía, su sentido común se lo impedirían (Pitol, 2007: 173).

\section{Bibliografía}

BorRÁs BETRIU, R. (2005): La guerra de los planetas. Barcelona, Ediciones B.

Bourdieu, P. (1989-1990): «El campo literario. Prerrequisitos críticos y principios de método», Criterios, 25-28, pp. 20-42.

(1999): Die Regeln der Kunst. Frankfurt am Main, Suhrkamp, 2001.

ECO, U. (1970): La definición del arte. Barcelona, Ediciones Roca.

GINER, J. R. (2013): «Un premio innecesario», Diario Información (28.03.2013), en http:// www.diarioinformacion.com/arte-letras/2013/03/28/premio-innecesario/1358172.html (última consulta, 29.07.2014).

HABERMAS, J. (1973): Kultur und Kritik. Frankfurt am Main, Suhrkamp.

LIDÓN, L. (2011): «Javier Marías recibe el premio de literatura europea como autor de una obra que expande la conciencia» (30.07.2011), en http://javiermariasblog.wordpress.com/2011/07/30/ javier-marias-recibe-el-premio-de-literatura-europea-como-autor-de-una-obra-que-expande-laconciencia/ (última consulta, 29.07.2014).

MANRiQue SAbogal, W. (2012): «Javier Marías rechaza el Nacional de Narrativa por Los enamoramientos», El País (25.10.2012), en http://cultura.elpais.com/cultura/2012/04/21/ actualidad/1334998646_622912.html (última consulta, 29.07.2014).

MUKǍ̌OVSKÝ, J. (1977): Función, norma y valor estético como hechos sociales. Barcelona, Gustavo Gili.

PITOL, S. (2007): «Vila-Matas premiado», en M. HerediA, ed., Vila-Matas portátil. Un escritor ante la crítica. Barcelona, Candaya.

VALLS, F. (2009): «Entre sólida y líquida: La prosa narrativa española en la época de las culturas (1986-2008)», en J. Gracia y D. RóDEnAs DE Moya, eds., Más es más. Sociedad y cultura en la España democrática, 1986-2008. Madrid, Iberoamericana.

VARGAS LlOSA, M (2009): «La civilización del espectáculo». Letras libres (Febrero 2009).

Vila-Matas, E. (1995) «Pujol y Marsé», en El traje de los domingos. Madrid, Huerga \&Fierro, 2006.

- (2003): Aunque no entendamos nada. Santiago de Chile, J. C. Sáez.

(2008): «Una narrativa invisible», en Y Pasavento ya no estaba. Buenos Aires, Mansalva.

(2010): Dublinesca. Barcelona, Seix Barral.

- (2013) «Editores y agentes (un vértigo)», en A. BADÍA, A. L. Blanc y M. García, eds., Géographies du vertige dans l'oeuvre d'Enrique Vila-Matas. Perpignan, Presses Universitaires de Perpignan.

VIÑAS, D. (2009): El enigma best-seller. Fenómenos extraños en el campo literario. Barcelona, Ariel. 